\title{
Potentially inappropriate medication use in nursing homes: an observational study using the NORGEP-NH criteria
}

\author{
Gunhild Nyborg ${ }^{*}$ (D, Mette Brekke, Jørund Straand, Svein Gjelstad and Maria Romøren
}

\begin{abstract}
Background: Frail residents in the nursing home sector call for extra care in prescribing. The Norwegian General Practice Nursing Home (NORGEP-NH) list of 34 explicit criteria for potentially inappropriate medication use in nursing homes was developed explicitly for this population. The aim of this study was to employ the NORGEP-NH Criteria to study the extent of potentially inappropriate medication use among nursing home residents and explore possible associated factors.

Methods: Cross-sectional observational pharmacoepidemiological study from residents in nursing homes in the county of Vestfold, Norway. Data collected 2009-11 included residents' demographic and clinical status and all medications, regular and on demand.

Results: 881 patients from 30 institutions (mean 85.9 years, 68.6\% female), were included. According to NORGEP$\mathrm{NH}, 43.8 \%$ were prescribed at least one potentially inappropriate regular medication, and $9.9 \%$ regularly received three or more potentially inappropriate medications. When also including a) the NORGEP-NH Deprescribing Criteria and b) including drugs prescribed for use as needed, $92.7 \%$ of all residents received medication that needs particular surveillance according to the NORGEP-NH. $69.7 \%$ of the nursing home residents used at least one psychotropic drug regularly. Female residents received more often than males at least one potentially inappropriate regular medication (OR 1.60, $\mathrm{p}=0.007$ ). Regarding the prescription of three or more concomitant psychotropic medications, odds ratio for females was $1.79(p=0.03)$ compared to males. Residents with the best performance in activities of daily living, and residents residing in long-term wards, had higher risk of using three or more psychotropic drugs. Use of multiple psychoactive drugs increased the risk of falls in the course of an acute episode of infection or dehydration (odds ratio $1.70, \mathrm{p}=0.009$ ).
\end{abstract}

Conclusions: Prevalence of potentially inappropriate medications in nursing homes according to the NORGEP-NH was extensive, and especially the use of multiple psychotropic drugs. The high prevalence found in this study shows that there is a need for higher awareness of medication use and side effects in the elderly population.

Trial registration: Retrospectively registered. Data obtained from clinical trial NCT01023763 registered with ClinicalTrials.gov 12/01/2009.

Keywords: Potentially inappropriate medication use, Elderly, Nursing homes, Drug safety, Explicit criteria, NORGEP-NH, Psychotropic medications

\footnotetext{
* Correspondence: gunhild.nyborg@medisin.uio.no

Department of General Practice/Family Medicine, HELSAM, Institute of Health

and Society, University of Oslo, P.o. Box 1130 Blindern, 0318 Oslo, Norway
}

(c) The Author(s). 2017 Open Access This article is distributed under the terms of the Creative Commons Attribution 4.0 International License (http://creativecommons.org/licenses/by/4.0/), which permits unrestricted use, distribution, and reproduction in any medium, provided you give appropriate credit to the original author(s) and the source, provide a link to the Creative Commons license, and indicate if changes were made. The Creative Commons Public Domain Dedication waiver (http://creativecommons.org/publicdomain/zero/1.0/) applies to the data made available in this article, unless otherwise stated. 


\section{Background}

Due to demographic changes and an intensified effort in community care of the elderly [1], residents in European nursing homes have over the past decades become increasingly frail, often with multiple active diagnoses [2]. The situation is similar in Norway, where a recent study found that the prevalence of dementia among Norwegian nursing home residents increased from $80.4 \%$ in 2004 to $84.3 \%$ in $2010-11$. The average resident is incapable of walking without assistance, and also needs assistance for other activities of daily living (ADL) [3]. Meanwhile, development in the field of pharmacology has given doctors a broader palette in their effort to treat discomfort and diseases. As a result, it is now common for nursing home residents to have medication lists of substantial length. A cross sectional study in eight European countries found that almost one out of four nursing home residents were subject to excessive polypharmacy (10 or more medications), whereas polypharmacy (5-9 drugs) was observed in one out of two [4]. A US study from 2004 found polypharmacy, defined as 9 or more medications, in $40 \%$ of nursing home residents [5].

Elderly are especially prone to side-effects and drug interactions due to physiological changes like reduced kidney, cognitive and sensory function, and altered pharmacokinetics and pharmacodynamics [6]. While medication use is crucial for symptom relief and reduction of morbidity and mortality, polypharmacy is also associated with an increased risk of adverse drug reactions (ADRs) [7, 8]. However, due to dementia and other conditions, many nursing home residents have problems expressing their opinion and experience regarding medication use, which may increase the risk of ADRs being unrecognized. Consequently, it is important that nursing home physicians are aware of the risks involved in medication use, and that medication reviews and deprescribing are prioritized tasks $[9,10]$.

Potentially inappropriate medications (PIMs) can be defined as drugs that pose more risks than benefits to the patients [11]. Several lists of explicit and implicit criteria have been developed for the surveillance of PIM use in a general elderly population [12-14]. The US Beers criteria have been widely used and were last updated in 2015 [15]. The Beers list reflects prescribing patterns and drugs marketed in the US. The STOPP list developed in Ireland in 2008, updated in 2015 [16], has gained increased popularity in Europe. The STOPP criteria require access to clinical information, giving rise to concern that the tool may be too comprehensive for some clinical and research purposes [17]. The NORGEP Criteria were developed in Norway in 2008 , intended for use in general practice and for a homedwelling elderly population [18].

However, multi-morbidity, frailty, and the end-of-life setting, imply that the nursing home population requires especially targeted tools for medication surveillance. For many years, the Beers 1991 list of explicit criteria for inappropriate medication use in nursing homes was the only list especially developed for the nursing home setting [11]. According to these criteria, about half of all nursing home residents have been reported to be exposed to PIMs [19-21]. The use of psychotropics is substantial in the nursing home setting, and is associated with ADRs and falls [22, 23]. In some research, the variable of three or more concomitant psychotropic drugs has been used as a substitute variable for potentially inappropriate psychotropic use [24, 25].

In order to have an updated tool for assessment of medication use in nursing homes that was also suited for the Norwegian pharmaceutical market, the Norwegian General Practice - Nursing Home (NORGEP-NH) criteria for potentially inappropriate medication use especially for elderly in nursing homes were developed through a threeround Delphi consensus process in 2012 [26] (see Table 3). In addition to the "Single substance" and "Combination" criteria parallel to those found in the original NORGEP criteria, the NORGEP-NH criteria also introduced a third category - the "Deprescribing" criteria. This category contains substances that are not inappropriate per se, but that need special attention in that the need for their continued use should be reassessed frequently.

\section{Aims}

The purpose of this study was to assess the level of potentially inappropriate medication use in elderly nursing home residents in Norway according to the NORGEP$\mathrm{NH}$ criteria. We also wanted to look at factors associated with both PIM use and the use of three or more psychotropic substances concomitantly. This is the first study to explore resident characteristics and clinical factors associated with PIMs according to these criteria.

\section{Methods}

This study was carried out in one of Norway's 19 counties. Eligible units were all 34 nursing homes in the county (a total of 1611 beds), of which four nursing homes declined to participate. The 30 participating nursing homes had 12-124 beds (median 41), in total 1379 beds. They had one to eight departments, and either one type of wards or a combination of wards: for rehabilitation, short term and long term care, palliative care, and special departments for patients with special needs due to behavioral and psychological symptoms of dementia.

This is a cross-sectional observational study based on medication data collected during a comprehensive pragmatic cluster randomized trial assessing whether a structured training program in administrating intravenous fluids and antibiotics in nursing homes could reduce hospital transfers and ensure high quality care locally [27]. The trial followed a stepped-wedge design with nursing homes allocated to the 
control group before the intervention and to the intervention group after the intervention, so that patients in need of intravenous treatment were treated in the local hospital before their nursing home received the intervention, and in the nursing homes after. For a thorough description of methods for the interventional study, see [27].

The participants in our study constitute the part of the nursing home population in need of antibiotic or intravenous fluid therapy during the study period. Data were collected from nursing home residents treated with oral antibiotics from November 2009 to December 2010 (1192 cases), and residents treated with intravenous fluids and/or intravenous antibiotics either in the nursing home or in the local hospital from November 2009 to December 2011 (330 cases). Some patients were represented several times in the interventional study: $66.1 \%$ were registered once during the study period, $20 \%$ with two episodes, and the remaining with three or more episodes requiring antibiotic or intravenous treatments. For the purpose of this study, we included data from only the first treatment episode (990 individual residents). Patients hospitalized with septicemia or hospitalized for additional diagnostics or treatment were excluded in the intervention trial. Further, we excluded patients $<70$ years, as the NORGEP-NH criteria were developed for nursing home residents $\geq 70$ years, leaving a total number of 914 patients. For 33 subjects (3.6\% of those eligible) medication lists were not available. These were also excluded from our study, leaving a total of 881 short-term as well as permanent nursing home residents in 30 of the 34 nursing homes in the county.

In each nursing home and in each hospital department, a nurse served as primary contact for the study team. The nurses were responsible for including the patients and recording patient information in data collection forms, and photocopying the patients' medication charts with both regular and pro re nata (PRN, as needed) drugs. For all cases, clinical data were recorded at enrollment (day 1 in the treatment course) and at predefined days during the course of the acute illness until day 30, including delirium assessed with Confusion Assessment Method (CAM) [28]. Activity of daily living (ADL) was measured by the Barthel Index [29] which was retrospectively estimated (score 1 to 20 with increasing level of $\mathrm{ADL}$ ) by a nurse familiar with the patient as of 14 days before the disease onset, thus representing the resident's habitual level of functioning. Falls were recorded as either "Falls with fracture or injury" within the course of 30 days into the acute episode or "Fall/Tendency of falls" as an "unspecific new symptom". The responses for these two variables did not always overlap. For the purpose of this study, the two variables were combined into one variable, "Falls". The variable "Death" was recorded as "Death on day $\mathrm{x}$ after the start of the episode", with cut-off set to 30 days after the episode.

Dementia could not be assessed as a possible explanatory variable due to poor quality of the underlying data.

\section{Statistics and analyses}

IBM SPSS Statistics $22^{\circ}$ (Armonk, New York, USA) statistical software was used for the prevalence analyses. Two SPSS syntaxes were developed for the calculation of PIMs according to the NORGEP-NH, one for substances in regular use only, and one also including PRN drugs.

STATA $^{\circ}$ (College Station, Texas, USA) was used for predictor analyses in form of bivariate and multivariate regression, with odds ratio (OR) as measure of effects size and the intra-cluster correlation coefficient (ICC) as a measure of variability between clusters.

Main outcome was the prevalence of PIMs according to the NORGEP-NH criteria. We looked at each indicator, and at the sum of PIMs per person, with and without PRN drugs.

Bivariate and multivariate predictor analyses were performed using a multilevel logistic regression model stratified on the nursing home level (xtmelogit). We performed predictor analyses for PIMs in total, and also for the single criterion "concomitant use of three or more psychotropic medications". All predictor analyses concern the use of regular medications (exclusive PRN drugs).

Variables with statistical significance in bivariate analyses and/or clinical relevance (such as death or delirium) were chosen for the final regression model. Contingency tables showed that the subdivisions of the categories made in the final model were meaningful in the sense that all categories contained an appropriate number of observations. The Akaike Information Criterion (AIC) was also employed when deciding which variables to include in our final, multivariate, mixed effects regression model.

Pearson's $r$ was used to check for relationship between the Barthel score and the number of drugs given on a regular basis, and between the total number of drugs given on a regular basis and the amount of PIMs.

The total number of medications was shown to have a close, approximately linear relationship to both the number of PIMs and the prescribing of 3 or more psychotropic drugs and we found a positive correlation between total number of drugs and both PIMs (Pearson's $r=0.36$, $p=0.000)$ and $3+$ psychotropic drugs $(r=0.338, \mathrm{p}=0.000)$. Therefore, the total number of medications given was treated as an effect mediator and was omitted as a variable in the regression analyses in order to avoid over-adjustment bias in the estimate of OR [30].

Barthel ADL scores were categorized in tertiles.

The ICC was obtained to examine the amount of variability between the nursing homes that was not explained by the variables in the model.

We used the Chi-square test $(p<0.05)$ to check for statistical differences between patients included in and patients excluded from our study. 


\section{Results}

Overall mean age was 85.9 (range 70-102), and 604 of the $881(68.6 \%)$ were female. 97 of the participants $(11.0 \%)$ died within 30 days into the study period.

For sample characteristics, see Table 1.

The average number of medications given to each patient on a regular basis was 6.7 (range 0-19). When including PRN medications, the average number of medications for each patient was 9.7 (range 1-25).

For those without medications lists, age range was 7497, mean age 84.1 years. The Chi-square test revealed no statistical differences between included and excluded patients regarding age and gender.

The NORGEP-NH Criteria and the prevalence of PIMs are given in Table 2.

Over $10 \%$ of the residents used antipsychotics, $30.9 \%$ used hypnotics, and $35.3 \%$ used antidepressants on a regular basis. Three or more psychotropic drugs were used concomitantly by $14.5 \%$ of residents on a regular basis. When including the drugs on the PRN medication list, $41.5 \%$ used three or more, and one out of ten (10.5\%) used five or more psychotropic drugs concomitantly (Table 3 ). $85.2 \%$ received one or more psychotropic substances, regularly or on demand.

Of the nursing home residents in this study, 43.8\% had at least one PIM, according to the NORGEP-NH criteria parts $A$ and $B$ (Table 3). When including PRN drugs, the percentage of residents affected by at least one PIM rose to $69.9 \%$. One in ten $(9.9 \%)$ was given three or more PIMs concurrently on a daily basis. Only $7.2 \%$ of residents did not receive any medication according to the NORGEP-NH Single substance, Combination, and Deprescribing criteria.

\section{Factors associated with potentially inappropriate medication}

We ran analyses for both PIMs in total, and for the specific criterion "Concomitant use of three or more psychotropic drugs", in the regression models. Bivariate and multivariate mixed effects regression results with odds ratios, confidence intervals and $p$-values for all residents are shown in Table 4. The results commented below are all from multivariate analyses.

Residents' age was not a significant predictor of PIMs or $3+$ psychotropic drugs when looking at residents in all wards. However, in an alternative regression model only addressing residents in long-term and dementia wards, the odds for receiving $3+$ psychotropic drugs significantly decreased with increasing age (OR 0.95, 95\% C.I. $0.92-0.99, p=0.02$ ) (not shown in table). We did not find clear non-linear associations when age was tested as categorical variable in various age groups.

Female residents had higher odds of receiving PIMs than male residents (OR $1.60, p=0.007)$. When analysing for $3+$ psychotropic medications the gender difference increased (OR 1.79, $p=0.03$ ). When analysing gender difference employing the alternative regression model only including residents living in long-term wards (comprised of long-time and dementia wards), OR for PIMs for female residents vs. male residents was 1.63 (95\% C.I. $1.01-2.66, p=0.04$ ). However, for $3+$ psychotropic drugs the odds for females increased to 2.91 (95\% C.I. 1.36-6.23, $p=0.006$ ) when only including residents in long-term facilities (not shown in table).

The odds of receiving PIMs were higher for the group with the highest ADL score. The odds of receiving 3+ psychotropic drugs was even higher for those with the highest ADL score, $O R=2.16(p=0.006)$ for the best functioning tertile compared to the group with the lowest ADL score. For only residents in long-term wards, this tendency was even stronger: The best functioning elderly in long-term care had an OR of 3.07 (95\% C. I. $1.5-6.3, p=0.002$, not shown in table) of receiving $3+$ psychotropic drugs compared to the group with the

Table 1 Sample characteristics

\begin{tabular}{|c|c|c|c|c|}
\hline & $\begin{array}{l}\text { Total number (\%) } \\
\text { in data set }\end{array}$ & $\begin{array}{l}\text { Number with medication } \\
\text { list (\%). Included in study }\end{array}$ & $\begin{array}{l}\text { Number without medication } \\
\text { list (\%). Not included in study }\end{array}$ & $\begin{array}{l}\text { Mean (range) among those } \\
\text { included in study }\end{array}$ \\
\hline Participants & $914(100)$ & $881(100)^{*}$ & $33(100)$ & \\
\hline \multicolumn{5}{|l|}{ Gender: } \\
\hline Female & $623(68.2)$ & 604 (68.6) & 19 (57.6) & \\
\hline Male & $291(31.8)$ & 277 (31.4) & $14(42.2)$ & \\
\hline Age (years): & & & & $85.9(70-102)$ \\
\hline$\leq 85$ & 401 (43.9) & $382(43.4)$ & 19 (57.6) & \\
\hline$>85$ & $513(56.1)$ & 499 (56.6) & $14(42.4)$ & \\
\hline Institutions & 30 & $30^{\mathrm{a}}$ & $16^{\mathrm{a}}$ & \\
\hline No. of beds & 1379 & & & $46.0^{b}(12-124)$ \\
\hline No. of incl. Cases & & $881(100)$ & & $29.4^{\mathrm{b}}(3-170)$ \\
\hline No. of NH doctors & 57 & & & $1.9^{\mathrm{b}}(1-6)$ \\
\hline
\end{tabular}

${ }^{\mathrm{a}}$ No. of institutions represented among patients with/without medication lists. ${ }^{\mathrm{b}} \mathrm{Per}$ institution

* significant at $p<0.05$ 
Table 2 Prevalence of potentially inappropriate medication use in nursing home residents $\geq 70$ years according to NORGEP-NH

\begin{tabular}{|c|c|c|c|}
\hline \multicolumn{4}{|c|}{ NORGEP-NH ${ }^{a}$ List of Explicit Criteria } \\
\hline \multicolumn{4}{|c|}{ A: Single Substance Criteria. The following should be avoided for regular use whenever possible: } \\
\hline 1. & Combination analgesic with codeine/paracetamol & 0.8 & 6.8 \\
\hline 2. & Tricyclic antidepressants (TCAs) for depression & 0.9 & 0.9 \\
\hline 3. & NSAIDs & 1.1 & 7.7 \\
\hline 4. & First generation antihistamines & 4.5 & 6.0 \\
\hline 5. & Diazepam & 1.4 & 10.7 \\
\hline 6. & Oxazepam: Dosage >30 mg/day & 0.8 & N/A \\
\hline 7. & Zopiclone: Dosage >5 mg/day & 14.1 & N/A \\
\hline 8. & Nitrazepam & 2.8 & 3.6 \\
\hline 9. & Flunitrazepam & 0.3 & 0.3 \\
\hline 10. & Chlometiazole & 1.2 & 8.7 \\
\hline 11. & Regular use of hypnotics & 30.9 & \\
\hline
\end{tabular}

B: Combination Criteria. The following drug combinations should be avoided whenever possible:

$\begin{array}{lll}\text { 12. Warfarin + NSAIDs } & 0.0 & 0.5 \\ \text { 13. Warfarin + SSRI/SNRI } & 1.6 & 1.6 \\ \text { 14. Warfarin + ciprofloxacin/ofloxacin/ erythromycin/ clarithromycin } & 0.3 & 0.5 \\ \text { 15. NSAIDs/coxibs + ACE-inhibitors/AT2-antagonists } & 0.2 & 1.1 \\ \text { 16. NSAIDs/coxibs + diuretics } & 0.6 & 3.9 \\ \text { 17. NSAIDs/coxibs + glucocorticoids } & 0.0 & 0.0 \\ \text { 18. NSAIDs/coxibs + SSRI/SNRIs } & 0.2 & 2.0 \\ \text { 19. ACE-inhibitors/AT2-antagonists + potassium or potassium-sparing diuretics } & 1.9 & 1.9 \\ \text { 20. Beta blocking agents + cardioselective calcium antagonists } & 0.0 & 0.1 \\ \text { 21. Erythromycin/clarithromycin + statins } & 0.1 & 0.1 \\ \text { 22. Bisphosphonate + proton pump inhibitors } & 1.6 & 1.7 \\ \text { 23. Concomitant use of three or more psychotropic drugs } & 14.5 & 41.5 \\ \text { 24. Tramadol + SSRls } & 1.4 & 6.1 \\ \text { 25. Metoprolol + paroxetine/fluoxetine/bupropion } & 0.0 & 0.0 \\ \text { 26. Metformin + ACE-inhibitors/AT2-antagonists + diuretics } & 1.0 & 1.0\end{array}$

C: Deprescribing criteria. Need for continued use should be reassessed:

\begin{tabular}{|c|c|c|c|}
\hline 27. & Anti-psychotics & 10.3 & 14.2 \\
\hline 28. & Anti-depressants & 35.3 & 35.5 \\
\hline 29. & Urologic spasmolytics & 0.7 & 0.7 \\
\hline 30. & Anticholinesterase inhibitors & 5.9 & 6.0 \\
\hline 31. & Drugs that lower blood pressure ${ }^{c}$ & 62.5 & 65.2 \\
\hline 32. & Bisphosphonates & 5.4 & 5.6 \\
\hline 33. & Statins & 12.1 & 12.1 \\
\hline 34. & General use of preventive medication & $N / A^{d}$ & $N / A^{d}$ \\
\hline
\end{tabular}

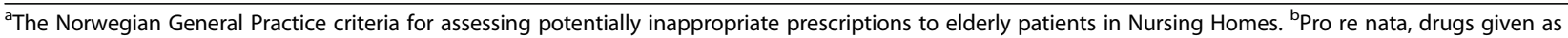
needed. 'Incl. in the figures: All drugs that have the lowering of blood pressure as primary outcome (i.e. hypertensives). Excl. drugs with lower blood pressure as side effect, wanted or unwanted. "Criterion 34 on the NORGEP-NH list, "General use of preventive medication", was not assessed in this paper, as information was lacking on whether medication was given for the purpose of treatment or prevention. Abbreviations: NSAIDs: Non-steroid anti-inflammatory drugs. SSRIs: Selective serotonin reuptake inhibitors. SRNIs: Selective norepinephrine reuptake inhibitors. Coxibs: Cyclooxygenase-2-selective inhibitors. ACE-inhibitors:

Angiotensin-converting enzyme inhibitors. AT2-antagonists: Angiotensin II receptor antagonists

lowest ADL score. They also had an OR of 2.64 (95\% C. I. 1.56-4.46, $p<0.001)$ of receiving PIMs compared to the lowest functioning group. When checking for relationship between the ADL score and the number of drugs given on a regular basis we did not find such correlation. 
Table 3 Prevalence of PIMs per person according to the NORGEP-NH criteria

\begin{tabular}{|c|c|c|c|c|c|c|}
\hline \multirow{2}{*}{$\begin{array}{l}\text { No. of PIMs } \\
\text { per person }\end{array}$} & \multicolumn{2}{|c|}{ NORGEP-NH $A^{1}+B^{2}+C^{3}$, prevalence $(\%)$} & \multicolumn{2}{|c|}{ NORGEP-NH $A^{1}+B^{2}$, prevalence (\%) } & \multicolumn{2}{|c|}{ No. of psychotropic drugs per person, prevalence (\%) } \\
\hline & $\begin{array}{l}\text { Excl. drugs } \\
\text { on demand }\end{array}$ & $\begin{array}{l}\text { Incl. drugs } \\
\text { on demand }\end{array}$ & $\begin{array}{l}\text { Excl. drugs } \\
\text { on demand }\end{array}$ & $\begin{array}{l}\text { Incl. drugs } \\
\text { on demand }\end{array}$ & $\begin{array}{l}\text { Excl. drugs } \\
\text { on demand }\end{array}$ & $\begin{array}{l}\text { Incl. drugs } \\
\text { on demand }\end{array}$ \\
\hline 0 & $108(12.3)$ & $64(7.3)$ & $495(56.2)$ & $265(30.1)$ & $267(30.3)$ & $130(14.8)$ \\
\hline 1 & $253(28.7)$ & $163(18.5)$ & $163(18.5)$ & $185(21.0)$ & $290(32.9)$ & $182(20.7)$ \\
\hline 2 & $211(24.0)$ & $161(18.3)$ & $136(15.4)$ & $181(20.5)$ & $196(22.2)$ & $203(23.0)$ \\
\hline 3 & $142(16.1)$ & $151(17.1)$ & $63(7.2)$ & $138(15.7)$ & $86(9.8)$ & $160(18.2)$ \\
\hline 4 & $80(9.1)$ & $130(14.8)$ & $20(2.3)$ & $72(8.2)$ & $37(4.2)$ & $113(12.8)$ \\
\hline 5 & $52(5.9)$ & $104(11.8)$ & $3(0.3)$ & $22(2.5)$ & $4(0.5)$ & $53(6.0)$ \\
\hline 6 & $26(3.0)$ & $57(6.5)$ & 0 & $13(1.5)$ & $1(0.1)$ & $29(3.3)$ \\
\hline 7 & $5(0.6)$ & $29(3.3)$ & $1(0.1)$ & $2(0.2)$ & 0 & $8(0.9)$ \\
\hline 8 & $3(0.3)$ & $13(1.5)$ & 0 & $3(0.3)$ & 0 & $2(0.2)$ \\
\hline 9 & 0 & $3(0.3)$ & 0 & 0 & 0 & $1(0.1)$ \\
\hline 10 & $1(0.1)$ & $5(0.6)$ & 0 & 0 & 0 & 0 \\
\hline 11 & 0 & $1(0.1)$ & 0 & 0 & 0 & 0 \\
\hline SUM & 881 (100\%) & 881 (100\%) & 881 (100\%) & 881 (100\%) & 881 (100\%) & 881 (100\%) \\
\hline
\end{tabular}

${ }^{1} \mathrm{~A}$ : Single substance criteria ${ }^{2} \mathrm{~B}$ : Combination criteria ${ }^{3} \mathrm{C}$ : Deprescribing criteria

Number of people affected, with percentages

There were no significant differences between the different types of wards regarding total numbers of PIMs. However, when looking at the prescribing of $3+$ psychotropic drugs, the odds were significantly higher for residents in long-term wards, dementia wards, and in wards with combined longand short-term beds, as compared to residents in shortterm wards, rehabilitation wards and palliative wards.

In the multilevel model, an ICC estimate of 0.06 was obtained, hence $6 \%$ of the variability in PIMs total can be attributed to differences between nursing homes. ICC increased to 0.16 when analysing residents receiving $3+$ psychotropic drugs. When looking at only residents in long-term facilities, the difference between the nursing homes measured by the ICC increased to 0.14 for PIMs and 0.26 for $3+$ psychotropic drugs.

Residents receiving 3+ psychotropic drugs had higher odds of falls in the course of the infection or dehydration episode, with or without fracture (OR 1.70, $p=0.04)$. We found no significant results on either PIMs or psychotropic drugs regarding delirium or death following in the course of the infection.

We tested a regression model where the outcome variable was medications lowering blood pressure, to see if residents using these substances were more prone to falls than other residents, but we did not find any such relationship in these data.

\section{Discussion}

Summary of results and comparison to previous literature The prevalence of PIMs according to the NORGEP-NH Single Substance and/or Combination Criteria was
43.8\% excluding, 69.9\% including PRN medication. The use of psychotropic medications was extensive. Females were at higher risk of receiving PIMs and multiple psychotropic drugs, especially when in long-term facilities. Those with good ADL-functioning were at higher risk of receiving multiple psychotropic drugs. The use of multiple psychotropic drugs increased the risk of falls in the course of an infection or dehydration episode.

The use of first generation antihistamines is not included in the criterion regarding "Concomitant use of three or more psychotropic drugs". Among the 4.5\% using first generation antihistamines, $45 \%$ also used three or more psychotropics. Thus, these residents had yet an additional burden regarding risk of falls and oversedation [31].

Clomethiazole is still in use for neuropsychiatric symptoms like agitation and aggression in Norway, as one of few countries, in spite of a considerably higher mortality than other substances used on same indications, and poor documentation on safety [32]. Almost one in ten (8.7\%) had clomethiazole listed as a regular or PRN drug.

When analyzing "The use of TCA against depression", we did not have information on whether the resident was using TCA to treat depression or as adjuvant treatment of chronic pain. The prevalence for this indicator may therefore be higher than the number actually using TCAs for depression. The basis for this indicator is that the anticholinergic effects of TCAs are potentially harmful for the frail elderly [33, 34]. However, Coupland et al. found newer antidepressants to be associated with an even higher risk of falls than TCAs [35]. The efficacy of antidepressants in this population is not clearly established [35-37]. There 
Table 4 Factors associated with potentially inappropriate medications, and 3+ concomitant psychotropic medications according to NORGEP-NH Single Substance and Combination Criteria ${ }^{a}$

\begin{tabular}{|c|c|c|c|c|c|c|c|c|c|}
\hline \multirow[b]{2}{*}{ Variable } & \multirow[b]{2}{*}{$\begin{array}{l}\text { No. of residents } \\
\text { n (valid cases, \%) }\end{array}$} & \multicolumn{4}{|c|}{ PIMs according to NORGEP-NH Criteria 1-26 } & \multicolumn{4}{|c|}{$3+$ concomitant psychotropic drugs } \\
\hline & & $\begin{array}{l}\text { Bivariate analyses } \\
\text { OR }(95 \% \text { C.I.) }\end{array}$ & p & $\begin{array}{l}\text { Multivariate analyses } \\
\text { OR (95\% C.I.) }\end{array}$ & p & $\begin{array}{l}\text { Bivariate analyses } \\
\text { OR ( } 95 \% \text { C.I.) }\end{array}$ & $p$ & $\begin{array}{l}\text { Multivariate analyses } \\
\text { OR (95\% C.I.) }\end{array}$ & $p$ \\
\hline $\operatorname{Age}^{b} n=881$ & 881 & $0.99(0.97-1.01)$ & 0.34 & $0.98(0.96-1.01)$ & 0.17 & $0.99(0.96-1.02)$ & 0.59 & $0.98(0.95-1.01)$ & 0.18 \\
\hline $\begin{array}{l}\text { Gender: } \\
\mathrm{n}=881 \text { Male }\end{array}$ & $277(31.4)$ & 1 (Ref) & & 1 (Ref) & & 1 (Ref) & & 1 (Ref) & \\
\hline Female & $604(68.6)$ & $1.38(1.02-1.86)$ & $0.03^{*}$ & $1.60(1.14-2.24)$ & $<0.01^{*}$ & $1.72(1.09-2.71)$ & $0.02^{*}$ & $1.79(1.06-3.01)$ & $0.03^{*}$ \\
\hline $\begin{array}{l}\text { Barthel }^{c} \\
n=8070-5\end{array}$ & $314(35.6)$ & 1 (Ref) & & 1 (Ref) & & 1 (Ref) & & 1 (Ref) & \\
\hline $6-10$ & $259(29.4)$ & $1.28(0.91-1.80)$ & 0.16 & $1.36(0.95-1.94)$ & 0.09 & $1.26(0.75-2.10)$ & 0.38 & $1.41(0.83-2.42)$ & 0.21 \\
\hline $11-20$ & $234(26.6)$ & $1.30(0.91-1.85)$ & 0.15 & $1.32(0.91-1.92)$ & 0.15 & $1.83(1.11-3.04)$ & $0.02^{*}$ & $2.16(1.25-3.73)$ & $0.01^{*}$ \\
\hline Falls: $n=830 \mathrm{No}$ & $663(75.3)$ & 1 (Ref) & & 1 (Ref) & & 1 (Ref) & & 1 (Ref) & \\
\hline Yes & $167(19.0)$ & $1.09(0.77-1.54)$ & 0.47 & $1.10(0.76-1.36)$ & 0.60 & $1.84(1.16-2.91)$ & $<0.01^{*}$ & $1.70(1.03-2.80)$ & $0.04^{*}$ \\
\hline $\begin{array}{l}\text { Delirium }{ }^{\text {: }} \\
n=877 \text { No }\end{array}$ & 807 (91.6) & 1 (Ref) & & 1 (Ref) & & 1 (Ref) & & 1 (Ref) & \\
\hline Yes & $70(7.9)$ & $0.93(0.56-1.55)$ & 0.78 & $0.95(0.51-1.76)$ & 0.88 & $1.22(0.62-2.42)$ & 0.57 & $1.21(0.52-2.83)$ & 0.66 \\
\hline $\begin{array}{l}\text { Deathe }: n=897 \\
\text { No }\end{array}$ & 782 (88.8) & 1 (Ref) & & 1 (Ref) & & 1 (Ref) & & 1 (Ref) & \\
\hline Yes & 97 (11.0) & $0.75(0.48-1.17)$ & 0.21 & $0.80(0.47-1.36)$ & 0.41 & $0.97(0.52-1.78)$ & 0.91 & $1.67(0.82-3.38)$ & 0.16 \\
\hline $\begin{array}{l}\text { Ward: } n=837 \\
\text { Rehabilitation }\end{array}$ & $58(6.6)$ & 1 (Ref) & & 1 (Ref) & & 1 (Ref) & & 1 (Ref) & \\
\hline Short-time & 158 (17.9) & $0.74(0.30-1.39)$ & 0.44 & $0.87(0.39-1.94)$ & 0.73 & $2.30(0.54-9.87)$ & 0.26 & $2.75(0.60-12.60)$ & 0.19 \\
\hline Long-time & 364 (41.3) & $1.25(0.52-2.35)$ & 0.57 & $1.61(0.72-3.62)$ & 0.25 & $5.08(1.27-20.23)$ & $0.02^{*}$ & $7.48(1.74-32.08)$ & $<0.01^{*}$ \\
\hline Short-/longtime & $100(11.4)$ & $1.56(0.59-3.17)$ & 0.31 & $2.12(0.86-5.26)$ & 0.10 & $5.92(1.34-26.27)$ & $0.02^{*}$ & $7.20(1.51-34.36)$ & $0.01^{*}$ \\
\hline Dementia & $114(12.9)$ & $1.11(0.41-2.16)$ & 0.80 & $1.19(0.50-2.83)$ & 0.70 & $7.24(1.68-31.27)$ & $<0.01^{*}$ & $7.70(1.68-35.32)$ & $<0.01^{*}$ \\
\hline Palliative & $46(5.2)$ & $1.51(0.56-3.61)$ & 0.38 & $1.98(0.73-5.40)$ & 0.18 & $1.88(0.30-11.71)$ & 0.50 & $2.04(0.30-13.99)$ & 0.47 \\
\hline
\end{tabular}

${ }^{a}$ Bivariate and multivariate mixed effects regression analyses stratified on the nursing home level. ${ }^{b}$ Continuous variable. ${ }^{\mathrm{c}} \mathrm{No}$. of residents in each tertile. ${ }^{\mathrm{d}} \mathrm{In}$ the course of the infection. ${ }^{e}$ Within 30 days of study inclusion *significant at $p<0.05$

Regression model including all nursing home residents

is a need for further research into effects and side effects of antidepressant drugs in this population.

The total PIM prevalence of $43.8 \%$ in our study is in accordance with a nursing home study that according to the STOPP criteria reported a prevalence rate of $46.2 \%$ [21], one study employing the Beers criteria that found a prevalence rate of $46.5 \%$ [20], and another $50 \%$, the latter looking at residents with a minimum of three months' stay [19]. A Norwegian study reporting prevalence rates of PIMs in nursing homes based on 28 of the 36 original NORGEP criteria developed for home-dwelling elderly found a prevalence of PIM use at 31\% [38]. A recent study employing the NORGEP-NH criteria found that PIMs in Norwegians nursing homes have increased over the years 1997-2011, while the average number of drugs also increased over the same time period [39].

Ruths et al. found an increase in the regular use of psychotropic drugs among Norwegian nursing home residents from $57.6 \%$ in 1997 to $70.5 \%$ in 2009 [40]. This is in accordance with our finding of $69.7 \%$. It has been shown that deprescribing of anti-psychotic drugs in nursing home populations may improve inhabitants' function [41]. The high level of psychotropic medication use in the nursing home population is concerning, considering the limited effects and the high probability for serious side effects. This especially applies to antipsychotics used for behavioural and psychological symptoms of dementia (BPSD) [41-46].

We found that residents living in long-term facilities had higher odds of receiving multiple psychotropic drugs than elderly in short-term wards, rehabilitation wards or palliative care units, and among these, the elderly with the best preserved level of functioning had the highest odds of receiving three or more psychotropic drugs. This seemingly counter-intuitive result was not explained by a higher rate of deprescribing in the lowest functioning group, as we found no correlation between the ADL score and the number of drugs given on a regular basis. Instead, it seemed likely that the better functioning residents receive more psychotropic drugs, at least partly, as treatment for 
agitation, confusion and other neuropsychiatric symptoms in dementia, assuming the prevalence of dementia is even higher in long-term facilities than in all facilities as a total. This interpretation is consistent with the results from a recent multinational European study, where the strongest correlate of antipsychotic drug use was found to be severe behavioral symptoms [47], and Lovey et al. [48] who found that the use of antipsychotics was correlated to aggressive, verbally disruptive and wandering behavior and the ability to rise from a chair. This finding also suggests that the level of ADL could act as a confounder in analyses regarding the use of multiple psychotropic drugs in studies where one cannot correct for ADL as a variable as was done here.

There was an unexplained variability between the nursing homes regarding the prescribing of multiple psychotropic substances, as shown by the larger ICC between nursing homes, suggesting some degree of individual differences in prescription practice between doctors, or different prescription tradition between the different nursing homes. This is consistent with findings of two other studies revealing large unexplained variance between nursing homes regarding prescribing of antipsychotics to residents often lacking a clear indication $[49,50]$.

Some studies have demonstrated increased levels of falls with increasing levels of PIMs [51, 52]. In this study, we found the risk of falls in the course of an acute infection or dehydration to increase for those who received multiple psychotropic drugs, but there was no clear such association when looking at the number of PIMs as a whole. We did not find a relationship between a tendency of falls and the number of blood pressure lowering substances. In a systematic review from 2007, Hartikainen et al. found [23] antihypertensive drugs to be weakly associated with falls, and psychotropics - mainly benzodiazepines, antidepressants, and antipsychotics - to be strongly associated with falls in the elderly.

The gender differences found in our study are consistent with results from a large national study of homedwelling elderly in Norway conducted in 2008 [53], which found an odds ratio for females for receiving one or more PIMs of 1.60. There is still a need to explore further the reasons behind these differences.

\section{Strengths and limitations}

This study is based on comprehensive information about both regular medications and medications given on demand. In addition, the clinical information provided gave an opportunity to study some clinical factors related to PIM use in this setting. The different statistical models yielded robust results regarding significant and nonsignificant outcomes.

The patients included in this study were selected based on their need of antibiotic or fluid treatment for acute infection or dehydration. This selection could imply a bias towards the more frail of the residents. However, infections are common among nursing home residents and the proportion that receive antibiotic treatment each year is substantial $[54,55]$. We do not have access to the exact number of those included in this study in relation to the total number of residents in the 30 nursing homes, partly due to high turnover of residents and partly because this was beyond the scope of the intervention trial [27]. The county of Vestfold has 1379 nursing home places in total (for all 34 nursing homes and all age groups). Our selection of 881 patients implies that this study encompasses a fairly high proportion of the residents in the participating nursing homes. Importantly, the study design opened up for a chance to study how PIMs may affect the frail population of nursing home residents when they encounter acute illness.

Medication lists were recorded on day 1 of inclusion into the original interventional trial. As we based our analyses solely on the medication lists recorded at inclusion in the interventional trial, the intervention per se did not influence the results of our study.

The observational design allows us to analyse factors that are related to PIMs, and to $3+$ psychotropics. However, this methodology does not allow us to say whether the one or the other factor is causing this relationship, or whether a common third variable (confounder) is the cause of the association [56].

\section{Implications for further research and practice}

The highly prevalent use of PIMs in nursing homes found in this study shows that there is a need for intensified measures towards this problem. The topic should be prioritized both in research and in educational efforts in nursing home medicine in order to optimize patient treatment. The complexity of the task of prescribing to this population should be recognized by health administrators to ensure that prescribers are given sufficient resources.

However, although the high prevalence of psychotropic drugs and of PIMs in general shown here is of concern, it is important that elderly people are not withheld from efficient pharmacological treatment. Notably, adequate management of pain has been shown to reduce other use of psychotropic medications [57]. There may well be instances where the use of substances on lists as the NORGEP-NH may be appropriate. Explicit criteria like the NORGEP-HN and Beers' criteria are meant to heighten the awareness of clinicians and caregivers to the use of these substances and the risk involved: "The criteria are designed to support, rather than supplant, good clinical judgment." [58].

Studies over the past few years have demonstrated the widespread problem of potentially inappropriate prescribing in elderly throughout the world [53, 59-64]. There is a known relationship between ADRs and hospitalization and death $[8,65]$. So far, there is conflicting evidence as to the link between PIMs and ADRs [66], and the effect of PIMs 
on mortality, morbidity and quality of life (QoL) [67-77]. Some studies find increased hospitalization and mortality rates and reduced QoL with increasing drug burden [75]. Medication reviews has been advocated as a means to reduce the prevalence of PIMs in nursing homes [78]. However, a recent systematic review and meta-analysis that looked at the effect of medication reviews on nursing home resident's mortality or hospitalization found no clear correlation [79]. There is thus a need for more research into the impact of PIMs, and how we best are to reduce their prevalence [80, 81].

\section{Conclusion}

This study analyzed potentially inappropriate medication use in nursing homes according to the NORGEP-NH criteria. We found a high prevalence of PIMs, and among these, the use of psychotropic drugs was especially prevalent. Females were at higher risk of receiving both PIMs and multiple psychotropic drugs concurrently. Residents in longterm wards, and residents with a better-preserved ADL, had a higher risk of receiving multiple psychotropic drugs. The use of multiple psychotropic drugs increased the risk of falls in the course of an infection or dehydration episode.

A prevalence of PIMs of this magnitude reveals a need for targeted measures.

\section{Abbreviations \\ ACE-inhibitors: angiotensin-converting enzyme inhibitors; ADR: adverse drug reaction; ARB: angiotensin receptor blockers; AT2-antagonists: angiotensin II receptor antagonists; BPSD: Behavioural and Psychological Symptoms of Dementia; Coxibs: cyclooxygenase-2-selective inhibitors; $\mathrm{NH}$ : nursing home; NORGEP-NH Criteria: Norwegian General Practice - Nursing Home Criteria; NSAIDs: non-steroid anti-inflammatory drugs; OR: odds ratio; PIM: potentially inappropriate medication; PRN: pro re nata (medication given on demand only); QoL: quality of life; RCT: randomized controlled trial; SRNIs: selective norepinephrine reuptake inhibitors; SSRIs: selective serotonine reuptake inhibitors; TCAs: tricyclic antidepressants}

\section{Acknowledgements}

The 3iV project is a collaborative project between 30 participant nursing homes in Vestfold, Norway, the Vestfold Hospital Trust, Centre for Development of Institutional and Home Care Services, the University College of Southeast Norway, and the University of Oslo. The authors would like to thank all those who participated in the planning and executing of this study. We would also like to thank statistician Ibrahimu Mdala at the Department of General Practice/Family Medicine, Institute of Health and Society, University of Oslo, Norway for his assistance.

\section{Funding}

The project was funded by General Practice Research Fund (AMFF) hosted by the Norwegian medical Association. The AMFF had no role in the design, conduct, analyses or reporting of this study.

\section{Availability of data and materials}

The datasets used and/or analyzed during the current study is available from the corresponding author on reasonable request, likewise the SPSS syntaxes used in the NORGEP-NH analyses.

Dr. Nyborg, Dr. Romøren and Dr. Gjelstad have had full access to all of the data in the study and take responsibility for the integrity of the data and the accuracy of the data analysis. The original data are those of Dr. Romøren.

\section{Authors' contributions}

All authors have read and approved the manuscript. Acquisition of data: MR, SG. Study concept and design: GN, MR, MB, JS, SG. Analysis of data: GN, SG. Interpretation of data: GN, MR, SG, MB, JS. Drafting of the manuscript: GN. Revision of the manuscript: GN, MR, MB, JS, SG. Funding: GN, MB, JS. Project supervision: GN, MR, MB, JS.

\section{Ethics approval and consent to participate}

The study was approved by the Regional Committee for Medical and Health Research Ethics (REK) (reference no. 2009/1584a-1). Written informed consent was obtained from all patients. In patients lacking decision-making capacity, written consent was collected from next of kin. The 3iV study is reported in accordance with the Consort 2010 extension to cluster randomised trials and the suggested modifications to the Consort 2010 cluster extension for reporting of stepped wedge cluster randomised trials $[27,82]$. Trial registration with ClinicalTrials.gov: NCT01023763.

\section{Consent for publication}

Not applicable.

\section{Competing interests}

The authors report no conflicts of interest. The authors alone are responsible for the content and writing of the paper.

\section{Publisher's Note}

Springer Nature remains neutral with regard to jurisdictional claims in published maps and institutional affiliations.

Received: 25 January 2017 Accepted: 6 September 2017

Published online: 19 September 2017

\section{References}

1. Carpenter I, Gambassi G, Topinkova E, Schroll M, Finne-Soveri H, Henrard JC, et al. Community care in Europe. The aged in home care project (AdHOC). Aging Clin Exp Res. 2004;16(4):259-69.

2. Onder G, Carpenter I, Finne-Soveri H, Gindin J, Frijters D, Henrard JC, et al. Assessment of nursing home residents in Europe: the services and health for elderly in long TERm care (SHELTER) study. BMC Health Serv Res. 2012;12:5.

3. Helvik AS, Engedal K, Benth JS, Selbaek G. Prevalence and severity of dementia in nursing home residents. Dement Geriatr Cogn Disord. 2015; 40(3-4):166-77.

4. Onder G, Liperoti R, Fialova D, Topinkova E, Tosato M, Danese P, et al. Polypharmacy in nursing home in Europe: results from the SHELTER study. J Gerontol A Biol Sci Med Sci. 2012;67(6):698-704.

5. Dwyer LL, Han B, Woodwell DA, Rechtsteiner EA. Polypharmacy in nursing home residents in the United States: results of the 2004 National Nursing Home Survey. Am J Geriatr Pharmacother. 2010:8(1):63-72.

6. Wehling M. Drug Therapy for the Elderly. Wehling M, editor: Springer; 2013.

7. Pirmohamed M, James S, Meakin S, Green C, Scott AK, Walley TJ, et al. Adverse drug reactions as cause of admission to hospital: prospective analysis of 18820 patients. BMJ. 2004;329(7456):15-9.

8. Ebbesen J, Buajordet I, Erikssen J, Brors O, Hilberg T, Svaar H, et al. Drug related deaths in a department of internal medicine. Arch Intern Med. 2001; 161(19):2317-23.

9. Scott IA, Hilmer SN, Reeve E, Potter K, Le Couteur D, Rigby D, et al. Reducing inappropriate polypharmacy: the process of deprescribing. JAMA Intern Med. 2015;175(5):827-34.

10. Gnjidic D, Le Couteur DG, Hilmer SN. Discontinuing drug treatments. BmjBrit Med J. 2014;349

11. Beers MH, Ouslander JG, Rollingher I, Reuben DB, Brooks J, Beck JC. Explicit criteria for determining inappropriate medication use in nursing home residents. UCLA division of geriatric medicine. Arch Intern Med. 1991;151(9):1825-32.

12. Chang CB, Chan DC. Comparison of published explicit criteria for potentially inappropriate medications in older adults. Drugs Aging. 2010;27(12):947-57.

13. Holt S, Schmiedl S, Thurmann PA. Potentially inappropriate medications in the elderly: the PRISCUS list. Deutsches Arzteblatt int. 2010;107(31-32):543-51.

14. Dimitrow MS, Airaksinen MS, Kivela SL, Lyles A, Leikola SN. Comparison of prescribing criteria to evaluate the appropriateness of drug treatment in individuals aged 65 and older: a systematic review. J Am Geriatr Soc. 2011; 59(8):1521-30 
15. By the American Geriatrics Society Beers Criteria Update Expert P. American Geriatrics Society 2015 updated beers criteria for potentially inappropriate medication use in older adults. J Am Geriatr Soc. 2015;63(11):2227-46.

16. O'Mahony D, O'Sullivan D, Byrne S, O'Connor MN, Ryan C, Gallagher P. STOPP/START criteria for potentially inappropriate prescribing in older people: version 2. Age Ageing. 2015;44(2):213-8.

17. Dalleur O, Feron JM, Spinewine A. Views of general practitioners on the use of STOPP\&START in primary care: a qualitative study. Acta Clin Belg. 2014;69(4):251-61.

18. Rognstad S, Brekke M, Fetveit A, Spigset O, Wyller TB, Straand J. The Norwegian general practice (NORGEP) criteria for assessing potentially inappropriate prescriptions to elderly patients. A modified Delphi study. Scand J Prim Health Care. 2009;27(3):153-9.

19. Lau DT, Kasper JD, Potter DE, Lyles A. Potentially inappropriate medication prescriptions among elderly nursing home residents: their scope and associated resident and facility characteristics. Health Serv Res. 2004;39(5):1257-76.

20. Perri M 3rd, Menon AM, Deshpande AD, Shinde SB, Jiang R, Cooper JW, et al. Adverse outcomes associated with inappropriate drug use in nursing homes. Ann Pharmacother. 2005;39(3):405-11.

21. Parsons C, Johnston S, Mathie E, Baron N, Machen I, Amador S, et al. Potentially inappropriate prescribing in older people with dementia in care homes: a retrospective analysis. Drugs Aging. 2012;29(2):143-55.

22. Leipzig RM, Cumming RG, Tinetti ME. Drugs and falls in older people: a systematic review and meta-analysis: I. Psychotropic drugs. J Am Geriatr Soc. 1999:47(1):30-9.

23. Hartikainen $\mathrm{S}$, Lonnroos $\mathrm{E}$, Louhivuori K. Medication as a risk factor for falls: critical systematic review. J Gerontol A Biol Sci Med Sci. 2007;62(10):1172-81.

24. Bell JS, Taipale HT, Soini H, Pitkala KH. Prognostic value of the quality indicator "concurrent use of three or more psychotropic drugs" among residents of long term-care facilities. Eur J Clin Pharmacol. 2009;65(11):1163-4. author reply 1

25. Lesén E, Petzold M, Andersson K, Carlsten A. To what extent does the indicator "concurrent use of three or more psychotropic drugs" capture use of potentially inappropriate psychotropics among the elderly. Eur J Clin Pharmacol. 2009;65(6):635-42

26. Nyborg G, Straand J, Klovning A, Brekke M. The Norwegian general practicenursing home criteria (NORGEP-NH) for potentially inappropriate medication use: a web-based Delphi study. Scand J Prim Health Care. 2015;33(2):134-41.

27. Romøren $M$, Gjelstad $S$, Lindbæk M. A structured training program for health workers in intravenous treatment with fluids and antibiotics in nursing homes: A modified stepped-wedge cluster-randomised trial to reduce hospital admissions. PLoS ONE. 2017;12(9):e0182619.

28. Inouye SK, van Dyck CH, Alessi CA, Balkin S, Siegal AP, Horwitz Rl. Clarifying confusion: the confusion assessment method. A new method for detection of delirium. Ann Intern Med. 1990;113(12):941-8.

29. Collin C, Wade DT, Davies S, Horne V. The Barthel ADL index: a reliability study. Int Disabil Stud. 1988;10(2):61-3.

30. Schisterman EF, Cole SR, Platt RW. Overadjustment bias and unnecessary adjustment in epidemiologic studies. Epidemiology. 2009;20(4):488-95.

31. Vetrano DL, La Carpia D, Grande G, Casucci P, Bacelli T, Bernabei R, et al. Anticholinergic medication burden and 5-year risk of hospitalization and death in nursing home elderly residents with coronary artery disease. J Am Med Dir Assoc. 2016;

32. Pentikainen PJ, Valtonen W, Miettinen TA. Deaths in connection with chlormethiazole (heminevrin) therapy. Int J Clin Pharmacol Biopharm. 1976; 14(3):225-30.

33. Fox C, Richardson K, Maidment ID, Savva GM, Matthews FE, Smithard D, et al. Anticholinergic medication use and cognitive impairment in the older population: the medical research council cognitive function and ageing study. J Am Geriatr Soc. 2011;59(8):1477-83.

34. Aizenberg D, Sigler M, Weizman A, Barak Y. Anticholinergic burden and the risk of falls among elderly psychiatric inpatients: a 4-year case-control study. Int Psychogeriatr. 2002;14(3):307-10.

35. Coupland C, Dhiman P, Morriss R, Arthur A, Barton G, Hippisley-Cox J. Antidepressant use and risk of adverse outcomes in older people: population based cohort study. BMJ. 2011;343:d4551.

36. Banerjee S, Hellier J, Dewey M, Romeo R, Ballard C, Baldwin R, et al. Sertraline or mirtazapine for depression in dementia (HTA-SADD): a randomised, multicentre, double-blind, placebo-controlled trial. Lancet. 2011;378(9789):403-11.

37. Bergh S, Selbaek G, Engedal K. Discontinuation of antidepressants in people with dementia and neuropsychiatric symptoms (DESEP study): double blind, randomised, parallel group, placebo controlled trial. BMJ. 2012;344:e1566.
38. Halvorsen $\mathrm{KH}$, Granas AG, Engeland A, Ruths S. Prescribing quality for older people in Norwegian nursing homes and home nursing services using multidose dispensed drugs. Pharmacoepidemiol Drug Saf. 2012;21(9):929-36.

39. Halvorsen $\mathrm{KH}$, Selbaek G, Ruths S. Trends in potentially inappropriate medication prescribing to nursing home patients: comparison of three cross-sectional studies. Pharmacoepidemiol Drug Saf. 2016;

40. Ruths S, Sorensen PH, Kirkevold O, Husebo BS, Kruger K, Halvorsen KH, et al. Trends in psychotropic drug prescribing in Norwegian nursing homes from 1997 to 2009: a comparison of six cohorts. Int J Geriatr Psychiatry. 2013;28(8):868-76.

41. Ruths S, Straand J, Nygaard HA, Aarsland D. Stopping antipsychotic drug therapy in demented nursing home patients: a randomized, placebocontrolled study-the Bergen District nursing home study (BEDNURS). Int J Geriatr Psychiatry. 2008:23(9):889-95.

42. Selbaek G, Kirkevold O, Engedal K. The course of psychiatric and behavioral symptoms and the use of psychotropic medication in patients with dementia in Norwegian nursing homes-a 12-month follow-up study. Am J Geriatr Psychiatry. 2008;16(7):528-36.

43. Schneider LS, Dagerman K, Insel PS. Efficacy and adverse effects of atypical antipsychotics for dementia: meta-analysis of randomized, placebocontrolled trials. Am J Geriatr Psychiatry. 2006;14(3):191-210.

44. Schneider LS, Dagerman KS, Insel P. Risk of death with atypical antipsychotic drug treatment for dementia: meta-analysis of randomized placebo-controlled trials. JAMA. 2005;294(15):1934-43.

45. Gill SS, Bronskill SE, Normand SL, Anderson GM, Sykora K, Lam K, et al. Antipsychotic drug use and mortality in older adults with dementia. Ann Intern Med. 2007;146(11):775-86.

46. Langballe EM, Engdahl B, Nordeng H, Ballard C, Aarsland D, Selbaek G. Short- and long-term mortality risk associated with the use of antipsychotics among 26,940 dementia outpatients: a population-based study. Am J Geriatr Psychiatry. 2014:22(4):321-31.

47. Foebel AD, Liperoti R, Onder G, Finne-Soveri H, Henrard JC, Lukas A, et al. Use of antipsychotic drugs among residents with dementia in European long-term care facilities: results from the SHELTER study. J Am Med Dir Assoc. 2014;15(12):911-7.

48. Lovheim H, Sandman P-O, Kallin K, Karlsson S, Gustafson Y. Relationship between antipsychotic drug use and behavioral and psychological symptoms of dementia in old people with cognitive impairment living in geriatric care. Int Psychogeriatr. 2006;18(4):713-26.

49. Chen Y, Briesacher BA, Field TS, Tjia J, Lau DT, Gurwitz JH. Unexplained variation across US nursing homes in antipsychotic prescribing rates. Arch Intern Med. 2010;170(1):89-95.

50. Ruths S, Straand J, Nygaard HA. Psychotropic drug use in nursing homesdiagnostic indications and variations between institutions. Eur J Clin Pharmacol. 2001;57(6-7):523-8.

51. Wilson NM, Hilmer SN, March LM, Cameron ID, Lord SR, Seibel MJ, et al. Associations between drug burden index and falls in older people in residential aged care. J Am Geriatr Soc. 2011:59(5):875-80.

52. Stockl KM, Le L, Zhang S, Harada AS. Clinical and economic outcomes associated with potentially inappropriate prescribing in the elderly. Am J Manag Care. 2010;16(1):e1-10.

53. Nyborg G, Straand J, Brekke M. Inappropriate prescribing for the elderly-a modern epidemic? Eur J Clin Pharmacol. 2012;68(7):1085-94.

54. Tobiassen T, Berild D, Hjortdahl P. Use of systemic antibiotics in a Norwegian nursing home. Tidsskr Nor Laegeforen. 2002;122(24):2376-8.

55. Sundvall PD, Stuart B, Davis M, Roderick P, Moore M. Antibiotic use in the care home setting: a retrospective cohort study analysing routine data. BMC Geriatr. 2015;15:71.

56. von Elm E, Egger M. The scandal of poor epidemiological research. BMJ. 2004;329(7471):868-9

57. Husebo BS, Ballard C, Sandvik R, Nilsen OB, Aarsland D. Efficacy of treating pain to reduce behavioural disturbances in residents of nursing homes with dementia: cluster randomised clinical trial. BMJ. 2011;343:d4065.

58. Steinman MA, Beizer JL, DuBeau CE, Laird RD, Lundebjerg NE, Mulhausen P. How to use the American Geriatrics Society 2015 beers criteria-a guide for patients, clinicians, health systems, and Payors. J Am Geriatr Soc. 2015;63(12):e1-7.

59. Tommelein E, Mehuys E, Petrovic M, Somers A, Colin P, Boussery K. Potentially inappropriate prescribing in community-dwelling older people across Europe: a systematic literature review. Eur J Clin Pharmacol. 2015;71(12):1415-27.

60. Davidoff AJ, Miller GE, Sarpong EM, Yang E, Brandt N, Fick DM. Prevalence of potentially inappropriate medication use in older adults using the 2012 beers criteria. J Am Geriatr Soc. 2015;63(3):486-500. 
61. Amann U, Schmedt N, Garbe E. Prescribing of potentially inappropriate medications for the elderly: an analysis based on the PRISCUS list. Deutsches Arzteblatt inter. 2012;109(5):69-75.

62. Wahab MS, Nyfort-Hansen K, Kowalski SR. Inappropriate prescribing in hospitalised Australian elderly as determined by the STOPP criteria. Int J Clin Pharm. 2012;34(6):855-62.

63. Vishwas HN, Harugeri A, Parthasarathi G, Ramesh M. Potentially inappropriate medication use in Indian elderly: comparison of Beers' criteria and screening tool of older Persons' potentially inappropriate prescriptions. Geriatr Gerontol Int. 2012;12(3):506-14.

64. Fadare JO, Agboola SM, Opeke OA, Alabi RA. Prescription pattern and prevalence of potentially inappropriate medications among elderly patients in a Nigerian rural tertiary hospital. Ther Clin Risk Manag. 2013;9:115-20.

65. Wester K, Jonsson AK, Spigset O, Druid H, Hagg S. Incidence of fatal adverse drug reactions: a population based study. Br J Clin Pharmacol. 2008;65(4):573-9.

66. Hamilton H, Gallagher P, Ryan C, Byrne S, O'Mahony D. Potentially inappropriate medications defined by STOPP criteria and the risk of adverse drug events in older hospitalized patients. Arch Intern Med. 2011;171(11):1013-9.

67. Chiatti C, Bustacchini S, Furneri G, Mantovani L, Cristiani M, Misuraca C, et al. The economic burden of inappropriate drug prescribing, lack of adherence and compliance, adverse drug events in older people: a systematic review. Drug Saf. 2012;35(Suppl 1):73-87.

68. Hill-Taylor B, Sketris I, Hayden J, Byrne S, O'Sullivan D, Christie R. Application of the STOPP/START criteria: a systematic review of the prevalence of potentially inappropriate prescribing in older adults, and evidence of clinical, humanistic and economic impact. J Clin Pharm Ther. 2013;38(5):360-72.

69. Fu AZ, Jiang JZ, Reeves JH, Fincham JE, Liu GG, Perri M 3rd. Potentially inappropriate medication use and healthcare expenditures in the US community-dwelling elderly. Med Care. 2007;45(5):472-6.

70. Bootman $J$, Harrison DL, Cox E. The health care cost of drug-related morbidity and mortality in nursing facilities. Arch Intern Med. 1997;157(18):2089-96.

71. Onder G, Landi F, Liperoti R, Fialova D, Gambassi G, Bernabei R. Impact of inappropriate drug use among hospitalized older adults. Eur J Clin Pharmacol. 2005;61(5-6):453-9.

72. Ishii S, Kojima T, Ezawa K, Higashi K, Ikebata Y, Takehisa Y, et al. The association of change in medication regimen and use of inappropriate medication based on beers criteria with adverse outcomes in Japanese long-term care facilities. Geriatr Gerontol Int. 2016;

73. Jano E, Aparasu RR. Healthcare outcomes associated with beers' criteria: a systematic review. Ann Pharmacother. 2007;41(3):438-47.

74. Budnitz DS, Shehab N, Kegler SR, Richards CL. Medication use leading to emergency department visits for adverse drug events in older adults. Ann Intern Med. 2007;147(11):755-65.

75. Pitkala $\mathrm{KH}$, Juola $\mathrm{AL}$, Kautiainen $\mathrm{H}$, Soini $\mathrm{H}$, Finne-Soveri UH, Bell JS, et al. Education to reduce potentially harmful medication use among residents of assisted living facilities: a randomized controlled trial. J Am Med Dir Assoc. 2014;15(12):892-8.

76. Klarin I, Wimo A, Fastbom J. The association of inappropriate drug use with hospitalisation and mortality: a population-based study of the very old. Drugs Aging. 2005;22(1):69-82.

77. Lau DT, Kasper JD, Potter DE, Lyles A, Bennett RG. Hospitalization and death associated with potentially inappropriate medication prescriptions among elderly nursing home residents. Arch Intern Med. 2005;165(1):68-74.

78. Helsedirektoratet. Veileder om legemiddelgjennomganger. In: https:// helsedirektoratet.no/Lists/Publikasjoner/Attachments/465/Neilederlegemiddelgjennomgang-IS-1998.pdf, editor.: Helsedirektoratet; 2012 (in Norwegian).

79. Wallerstedt SM, Kindblom JM, Nylen K, Samuelsson O, Strandell A. Medication reviews for nursing home residents to reduce mortality and hospitalization: systematic review and meta-analysis. Br J Clin Pharmacol. 2014;78(3):488-97.

80. George J, Elliott RA, Stewart DC. A systematic review of interventions to improve medication taking in elderly patients prescribed multiple medications. Drugs Aging. 2008;25(4):307-24.

81. Forsetlund L, Eike M, Gjerberg E, Vist G. Effect of interventions to reduce potentially inappropriate use of medicines in nursing homes: a systematic review of randomised controlled trials. The Norwegian Knowledge Centre for the Health Services, helsetjenesten Nkf: Oslo; 2010.

82. Hemming K, Haines TP, Chilton PJ, Girling AJ, Lilford RJ. The stepped wedge cluster randomised trial: rationale, design, analysis, and reporting. BMJ. 2015; 350:h391.

\section{Submit your next manuscript to BioMed Central and we will help you at every step:}

- We accept pre-submission inquiries

- Our selector tool helps you to find the most relevant journal

- We provide round the clock customer support

- Convenient online submission

- Thorough peer review

- Inclusion in PubMed and all major indexing services

- Maximum visibility for your research

Submit your manuscript at www.biomedcentral.com/submit 